\title{
REPORT OF THE NSW MIDWIVES DATA COLLECTION 1994
}

Lee Taylor, Epidemiology Branch

Margaret Pym, Information and Data Services Branch NSW Health Department

$\mathrm{T}$ he NSW Midwives Data Collection (MDC) report for 1994, the seventh annual report on the MDC, was released in November 1995. In response to the demand for information on birth centre deliveries, the 1994 report includes information on birth centre deliveries in addition to regular features.

The MDC is a population-based surveillance system covering all births in NSW public and private hospitals, as well as homebirths. It encompasses all livebirths and stillbirths of at least 20 weeks gestation or at least 400 grams birthweight.

The MDC relies on the attending midwife to complete a notification form when a birth occurs. The form includes demographic items and items on maternal health, the pregnancy, labour, delivery and perinatal outcomes. Completed forms are sent to the Data Collections Unit in the Information and Data Services Branch of the NSW Health Department, where they are compiled into the MDC database.

The following is a summary of the main points from the 1994 report.

\section{DEMOGRAPHIC INFORMATION}

A total of 87,984 births to 86,738 women was reported to the MDC for 1994. The number of reported births increased by 5.9 per cent from 83,098 in 1987. More than one-quarter of the State's births were to women resident in South Western Sydney and Western Sydney Areas.

Overall, 73.5 per cent of all reported confinements were to Australian-born women, including 1.8 per cent who were Aboriginal. Following recent trends, the proportion of confinements to women born in Asia continued to rise and comprised 9.2 per cent of all confinements in 1994, while confinements among European-born women continued to decrease and comprised 3.1 per cent in 1994.

Aboriginal mothers and mothers born in the Middle East tended to be younger than NSW mothers as a whole. One in five births among Aboriginal women was to teenagers.

\section{PREGNANCY PROFILE}

More than half ( 56.9 per cent) of the women who gave birth in 1994 reported having had their first antenatal check in the first trimester of pregnancy, about one-third (34.1 per cent) in the second trimester and about 5 per cent in the third trimester.

Of the 86,738 confinements, 85,453 were singleton, 1,185 were twin and 30 were triplet.

At least one obstetric complication was reported in 14.0 per cent of confinements. The most common complication was pregnancy-induced hypertension, which was reported in 5.8 per cent.

\section{PLACE OF DELIVERY}

Only 1.6 per cent of women who gave birth in 1994 had not booked into an obstetric facility before the onset of labour. The vast majority of births ( 96.5 per cent) took place in hospital. Almost 3 per cent of births took place in a birth centre and 0.2 per cent took place at home.

\section{BIRTH CENTRE BIRTHS}

The number of women planning to give birth in a birth centre increased from 723 in 1990 (0.8 per cent of confinements) to 3,252 ( 3.7 per cent) in 1994. Of the women who planned a birth centre delivery, 2,502 - about three-quarters - had a birth centre delivery ( 2.9 per cent of all confinements). Women having their first baby were more likely to be transferred to a labour ward for delivery than those having their second or subsequent child. About onefifth of women who were transferred had an epidural anaesthetic, suggesting that the need for pain relief may be an important reason for transfer.

As expected, planned birth centre deliveries were characterised by lower rates of obstetric intervention, such as episiotomy and instrumental delivery, compared with all NSW deliveries. However, mothers planning a birth centre delivery had higher rates of postpartum haemorrhage compared with all NSW mothers.

\section{LABOUR AND DELIVERY}

Onset of labour was spontaneous for 70.3 per cent of all births, 23.3 per cent of labours were augmented, and labour was induced in about one in five births. The rate of spontaneous onset of labour has remained relatively stable at about 70 per cent since 1987 . However, the rate of augmentation of labour increased from 17.3 per cent in 1987 to 23.3 per cent in 1994.

The rate of spontaneous cephalic vaginal delivery was 70.6 per cent in 1994, while the rate of vaginally delivered breech presentations was 1.1 per cent. The caesarean section rate for 1994 was 17.3 per cent; the rate was 15.9 per cent in 1987 and 17.1 per cent in 1993 . The rate of instrumental delivery declined from 13.9 per cent in 1987 to 10.8 per cent in 1994.

\section{BABY CHARACTERISTICS}

Overall 5.8 per cent of newborns were of low birthweight (less than 2,500 grams) and 6.4 per cent were born prematurely (less than 37 weeks gestation). The proportion of low birthweight infants born to Aboriginal women was 11.7 per cent - more than twice that of non-Aboriginal mothers - while the rate of prematurity among Aboriginal infants was also 11.7 per cent.

About one in six infants had a one-minute Apgar score of less than 7 and 2.5 per cent had a five-minute Apgar score of less than 7. Low Apgar scores (<7) at five minutes were most common among infants born by vaginal breech delivery (18.4 per cent) and emergency caesarean section (5.1 per cent).

The reported perinatal mortality rate, using the World Health Organisation definition ${ }^{1}$ was 7.7/1,000 total births. The reported perinatal mortality rate has continued to decrease from the 1987 figure of 8.8/1,000 births and has remained less than 8.0/1,000 in both 1993 and 1994.

\section{FURTHER INFORMATION}

Copies of the full report and further information are available from Ms Margaret Pym (phone 02391 9199) or Dr Lee Taylor (391 9223).

1. Birthweight of 500 grams or more, or (when birthweight is unavailable) gestational age of 22 weeks or more. 